\title{
Experience in the treatment of Crohn's disease of the large intestine
}

\author{
J. HOWEL JONES, J. E. LENNARD-JONES, AND H. E. LOCKHART-MUMMERY
}

From St. Mark's Hospital, London

EDITORIAL COMMENT Limited resection for localized disease with total colectomy for diffuse disease have given good results. Medical treatment has given symptomatic relief but in this series rarely gave permanent benefit. It is possible that with earlier recognition of the disease it will become appreciated that corticosteroids have a greater role to play than is apparent in this series.

In previous papers from this hospital, the clinical and pathological features of Crohn's disease of the large intestine have been reviewed. The present paper describes experience in the treatment of this condition.

As has been pointed out, the anatomical distribution and manifestations of this disease are very variable. Treatment has therefore differed from patient to patient but for the purpose of analysis similar treatments have been grouped together.

\section{SELECTION OF PATIENTS}

A survey has been made of 96 patients treated at St. Mark's Hospital up to the end of 1963 in whom a diagnosis of Crohn's disease of the large intestine was made. Many of these patients were referred to the hospital for surgical treatment and this series cannot therefore be regarded as reflecting the results of medical treatment in an unselected series. The criteria for diagnosis are those of LockhartMummery and Morson (1960 and 1964), and the anatomical classification used is also the same, namely, (1) diffuse involvement of most or the whole of the large intestine $(a)$ with disease of the terminal ileum, (b) without disease of the terminal ileum; (2) strictures of the large intestine $(a)$ with a single segment of diseased bowel, $(b)$ with multiple strictures separated by areas of normal intestine; (3) disease confined to the sigmoid colon, rectum, and anal canal. Patients have been followed up during 1964 and 1965 and information is complete in 95 of the 96 patients.

\section{MEDICAL TREATMENT}

Only 12 of the 96 patients in this series have so far been treated without intestinal resection or by-pass. Most patients have been treated medically before operation and the results of treatment with antibiotics, anti-tuberculous therapy, and corticosteroids at St. Mark's Hospital have been analysed.

Of the 12 patients who so far have not required intestinal resection or by-pass, seven suffer from ano-rectal lesions managed by local measures, four with more extensive disease are maintained in fair health by repeated courses of steroids, and one patient has died (see below).

Courses of chemotherapy and antibiotics have been given without apparent benefit. Thirteen patients received anti-tuberculous drug therapy without altering the course of the disease.

Twenty-four of the 96 patients were treated with corticotrophin or corticosteroids, 21 of whom were given systemic treatment (combined with topical corticosteroids in seven) and the remaining three patients received topical steroids alone (Table I). The initial dose of oral corticosteroids varied between $20 \mathrm{mg}$. and $60 \mathrm{mg}$. of prednisone daily; two patients received 80 units of corticotrophin daily. The duration of therapy was from two weeks to one year. Topical treatment consisted of retention enemas of $20 \mathrm{mg}$. of prednisolone 21-phosphate or 200-100 mg. of hydrocortisone hemisuccinate daily. The duration of topical treatment was from three weeks to three months. Prednisolone 21-phosphate, $5 \mathrm{mg}$., was also given by suppository to some patients but this treatment is not included in the present analysis.

Sixteen of the 24 patients improved initially with corticosteroid or corticotrophin treatment, but the improvement was not often maintained. Twenty of the patients have required surgical treatment, the majority within one year, owing to the failure of medical treatment. Follow-up of the remaining four 
TABLE I

RESULTS OF CORTICOSTEROID AND CORTICOTROPHIN TREATMENT

\begin{tabular}{|c|c|c|c|c|c|c|c|}
\hline \multirow[t]{3}{*}{ Type of Disease } & \multirow{3}{*}{$\begin{array}{l}\text { No. of } \\
\text { Patients }\end{array}$} & \multicolumn{2}{|l|}{ Therapy } & \multicolumn{4}{|l|}{ Follow-up 1} \\
\hline & & \multirow{2}{*}{$\begin{array}{l}\text { Systemic } \\
\pm \text { Topical }\end{array}$} & \multirow[t]{2}{*}{ Topical Only } & \multirow{2}{*}{$\begin{array}{l}\text { Early } \\
\text { Improvement }\end{array}$} & \multirow{2}{*}{$\begin{array}{l}\text { Continued } \\
\text { Medical } \\
\text { Treatment }\end{array}$} & \multicolumn{2}{|c|}{ Radical Surgery } \\
\hline & & & & & & $<$ One Year & > One Year \\
\hline \multirow{5}{*}{$\begin{array}{l}\text { Ileo-colic } \\
\text { Diffuse colic } \\
\text { Single stricture } \\
\text { Multiple strictures } \\
\text { Distal }\end{array}$} & 8 & 7 & 1 & 5 & 2 & 4 & $2(2,3$ yr. $)$ \\
\hline & 11 & 10 & 1 & 8 & 2 & 8 & $1(2 \mathrm{yr})$. \\
\hline & & & & & & & \\
\hline & 5 & 4 & 1 & 3 & & 3 & $2(2,2 \mathrm{yr})$. \\
\hline & 24 & 21 & 3 & 16 & 4 & 15 & 5 \\
\hline
\end{tabular}

${ }^{1}$ Length of follow-up is shown in brackets.

patients who have not required operation varies from one to three years. One patient requires continuous corticosteroids and the other three patients have required repeated courses.

Thus in this selected group of patients, often referred to this hospital for possible surgical treatment, initial improvement with corticosteroids or corticotrophin was often encouraging but late results were unsatisfactory.

\section{SURGICAL TREATMENT}

Analysis of surgical treatment has been restricted to diversion operations and resections. The indication for operation in each case has been disabling symptoms which have not responded to medical measures. Treatments have been divided into the following groups.

1 DIVERSION OPERATIONS In the hope that exclusion of the faecal stream would allow healing of the diseased area, a diversion operation was performed in 21 (ileostomy (11), colostomy (8) or by-pass with exclusion (2)) patients (Table II). The results have been disappointing in all but two cases. In the remaining 19 cases, a temporary remission of the disease has sometimes followed operation but recurrence of disease in the defunctioned bowel or extension of the disease to involve previous healthy bowel has necessitated resection, often within one year. Diversion was employed for severe anal ulceration in five patients; no improvement was noted and in two of them the anal lesion progressed.

Of the two cases in which improvement occurred, one patient with recurrent ileal and ano-rectal disease with fistulae remains well six years after resection of ileal disease and construction of an ileostomy. The perianal and recto-vaginal fistulae closed following local surgical treatment. The other patient, treated by a left iliac colostomy for rectal disease, remained well for eight years until his death at the age of 76 from a stroke.

2 SEGMENTAL RESECTION WITH ANASTOMOSIS Eighteen patients with disease apparently limited to a short length of colon have been submitted to limited resection with immediate anastomosis (Table III). Included in this group are eight patients with disease involving the terminal ileum and right colon who had a right hemicolectomy. The remaining patients had a segmental resection of the colon alone.

Follow-up shows that 11 of the patients were well one to $\mathbf{1 0}$ years later. Four patients needed further surgery, two for colonic recurrence and two for progressive rectal disease. The remaining three patients are in fair health only, one with recurrence at the anastomosis and two with ano-rectal disease. In several of these patients it was known that re-

TABLE II

RESULTS OF DIVERSION OPERATION

\begin{tabular}{|c|c|c|c|c|c|c|c|}
\hline \multirow[t]{3}{*}{ Type of Disease } & \multirow{3}{*}{$\begin{array}{l}\text { No. of } \\
\text { Patients }\end{array}$} & \multicolumn{3}{|c|}{ Type of Operation } & \multicolumn{3}{|l|}{ Follow-up } \\
\hline & & \multirow[t]{2}{*}{ By-pass } & \multirow{2}{*}{ Ileostomy } & \multirow[t]{2}{*}{ Colostomy } & \multirow{2}{*}{$\begin{array}{l}\text { No Further } \\
\text { Surgery }\end{array}$} & \multicolumn{2}{|c|}{ Resection Performed } \\
\hline & & & & & & $<$ One Year & $>$ One Year \\
\hline $\begin{array}{l}\text { Ileo-colic } \\
\text { Diffuse colic } \\
\text { Single stricture }\end{array}$ & $\begin{array}{l}6 \\
9\end{array}$ & 2 & $\begin{array}{l}3 \\
7\end{array}$ & $\begin{array}{l}1 \\
2\end{array}$ & 1 (6 yr.) & $\begin{array}{l}4 \\
5\end{array}$ & $\begin{array}{l}1 \text { (2 yr.) } \\
4(2,2,4,5 \text { yr.) }\end{array}$ \\
\hline Multiple strictures & 1 & & & 1 & 1 (8 yr.) & & \\
\hline Distal & 5 & & 1 & 4 & & 4 & 1 (2 yr.) \\
\hline Total & 21 & 2 & 11 & 8 & 2 & 13 & 6 \\
\hline
\end{tabular}


TABLE III

\begin{tabular}{|c|c|c|c|c|c|c|c|}
\hline \multirow{3}{*}{ Type of Disease } & \multirow{3}{*}{ No. of Patients } & \multicolumn{6}{|c|}{ RESULTS OF SEGMENTAL RESECTIONS } \\
\hline & & \multicolumn{3}{|c|}{ Type of Resection } & \multicolumn{3}{|l|}{ Follow-up } \\
\hline & & Right & Transverse & Left & Good Result & Fair & Further Resection \\
\hline Ileo-colic & 9 & 8 & & 1 & $\begin{array}{l}5(<1,1,2,4,8 \\
\text { yr. })\end{array}$ & 2 & 2 \\
\hline Diffuse colic & 3 & & & 3 & $2(1,3$ yr. $)$ & & 1 \\
\hline Single stricture & 2 & & & 2 & $2(3,10 \mathrm{yr})$. & & \\
\hline Multiple strictures & 1 & & 1 & & & & 1 \\
\hline Distal & 3 & & & 3 & $2(3,5 \mathrm{yr})$. & 1 & \\
\hline Total & 18 & 8 & 1 & 9 & 11 & 3 & 4 \\
\hline
\end{tabular}

section was incomplete but it was hoped that removal of the most severaly diseased segment would avoid the need for a permanent ileostomy or colostomy. The early results of these operations are promising but no conclusion can be drawn about the long-term benefits of segmental resection.

3 RECTAL EXCISION WITH COLOSTOMY Twelve patients have had the rectum excised for distal Crohn's disease, leaving them with a terminal colostomy (Table IV). In two of these patients, because the disease extended into the left colon, a left hemicolectomy with a terminal transverse colostomy was performed at the time of rectal excision.

The results of rectal excision have been very good during the follow-up period of one to 11 years. There has been a tendency to slow perineal healing,

\section{TABLE IV}

RESULTS OF EXCISION OF RECTUM WITH COLOSTOMY

Type of Disease No. of Patients Follow-up

Good Result Recurrence and Colectomy

Ileo-colic

Diffuse colic

Single stricture

Multiple strictures

Distal

$\begin{array}{rlr}1 & 1(2 \mathrm{yr} .) & \\ 1 & 1(9 \mathrm{yr} .) & \\ 10 & 9\left(1,2,3,3,3,^{1}\right. & 1^{1} \\ 12 & 4,6^{1} 9,11 \text { yr. } & \\ & 11 & 1\end{array}$

Tota1

12

4,

$1^{1}$

1

'Appendix involved by Crohn's Disease in some cases taking up to six months. Eleven of the 12 patients have been restored to full health. The disease recurred in the colon proximal to the colostomy two years after rectal excision in the only unsuccessful case.

4 COLECTOMY AND ILEOSTOMY Colectomy and ileostomy, without excision of the rectum, has been performed in four patients; all are well but three have persisting rectal disease. In 12 other patients this operation was performed as a preliminary to ileo-rectal anastomosis (three patients) or total colectomy with excision of the rectum (nine patients).

5 COLECTOMY WITH ANASTOMOSIS Colectomy with anastomosis was performed in 19 patients with colonic disease in whom the rectum appeared healthy (Table V). Five of the anastomoses were ileo-sigmoid, 12 were ileo-rectal, one was ileodescending, and one was caeco-rectal.

Eleven patients are well, five of them for at least eight years. Most have up to four bowel actions daily but do not regard this as a serious disability.

Two patients are in fair health, one has recurrent disease involving the ileum, and the other has a possible recurrence at the anastomosis.

Five patients have required further surgery, two for peri-anal Crohn's disease, one for a recurrence at the anastomosis, one for stenosis of the anastomosis without evidence of recurrent disease, and one for a band obstruction.

TABLE V

RESULTS OF COLECTOMY WITH ANASTOMOSIS AND CONSERVATION OF THE RECTƯM

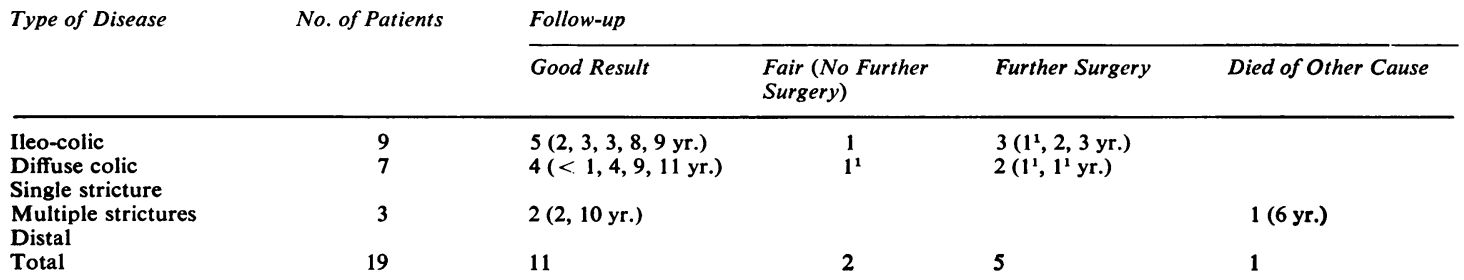

${ }^{1}$ Recurrent Crohn's disease at the anus or anastomosis. 
TABLE VI

RESULTS OF PROCTOCOLECTOMY

\begin{tabular}{|c|c|c|c|c|c|}
\hline \multirow[t]{2}{*}{ Type of Disease } & \multirow[t]{2}{*}{ No. of Patients } & \multicolumn{4}{|c|}{ Outcome } \\
\hline & & Death & Good Result & Fair Result & lleal Recurrence \\
\hline Ileo-colic & 5 & & $4(2,6,6,10 \mathrm{yr})$. & $1(5 \mathrm{yr})$. & \\
\hline Diffuse colic & 19 & 3 & $\begin{array}{c}14(1,1,1,2,2,2,2,2,3,5,6 \\
7,8,11 \text { yr. })\end{array}$ & 1 (1 yr.) & 1 (13 yr.) \\
\hline Single stricture & & & & & \\
\hline Multiple strictures & 2 & & $2(11,11$ yr. $)$ & & \\
\hline Distal & 2 & 1 & $1(4 \mathrm{yr})$. & & \\
\hline Total & 28 & 4 & 21 & 2 & 1 \\
\hline
\end{tabular}

The results of these operations have thus been good in 11 of 19 patients. The disease has definitely recurred in four patients, necessitating resection of the rectum and construction of an ileostomy in three.

6 PRoctocolectomy Proctocolectomy was performed in 28 patients, most of whom had diffuse disease (Table VI). In all save four patients, proctocolectomy was performed in two or more stages, 17 patients having had a previous partial colectomy and seven a previous ileostomy or colostomy.

The results of the operation were generally good and 21 patients have remained well, 10 of them for five or more years. Four patients have died, two in the post-operative period, one from peritonitis and one from intestinal obstruction, a third from spreading perineal sepsis two and a half years after rectal excision, and the fourth committed suicide three years after operation. One patient, of particular interest, developed a recurrence of Crohn's disease in the terminal ileum 13 years after the proctocolectomy. There was no evidence of ileal disease in this patient's first operation specimen. Of the remainder, one patient who had ileo-colic disease has persisting abdominal pain, though there was no evidence of recurrent disease at laparotomy; one patient is well though the perineal wound is incompletely healed one year after operation. Healing of the perineum was slow in 11 patients and in the patient who died of perineal sepsis it never healed.

\section{DEATHS}

Seven of the 96 patients have died during the period of follow-up and in five this was related to the disease. There were two post-operative deaths after proctocolectomy. One patient died of spreading ischiorectal sepsis two and a half years after the final stage of proctocolectomy. A girl of 21 who had had a proctocolectomy committed suicide three years later. A patient who had received corticosteroids died, probably of adrenal failure, at home.

\section{DISCUSSION}

The results reported here suggest that Crohn's disease of the large intestine is usually a chronic disorder with a low mortality, resistant to medical treatment, and often responding to surgical resection of the diseased bowel. While this impression may be correct, it cannot be substantiated until methods for pre-operative diagnosis permit analysis of a representative series of cases. The present series cannot be regarded as representative of an unselected series because many patients were transferred to St. Mark's Hospital for operation after unsuccessful medical treatment elsewhere and because the diagnosis of Crohn's disease of the large intestine is at present often made only after pathological examination of a surgical specimen.

The results of medical treatment in this series were disappointing. These poor results may have been due to selective factors already discussed. Antibiotics, chemotherapy, and anti-tuberculous therapy apparently gave little, if any, benefit. Corticosteroids and corticotrophin frequently brought about temporary improvement, particularly in acute disease, but subsequent relapse or deterioration necessitated surgical treatment in most cases. In some cases of ano-rectal disease, topical corticosteroids were apparently beneficial, allowing medical management with relief of symptoms, though usually with little objective improvement.

Many patients have had more than one major operation before surgical treatment was successful. In every case, the minimal procedure which might give benefit was performed first. The simplest procedure, diversion of the faecal stream, was rarely successful in relieving symptoms. The disease in the defunctioned bowel tended to persist, and often progressed, until resection or excision was undertaken.

The policy of performing a limited resection where possible has apparently been justified by the results so far. Eleven of 18 patients remain well after segmental resection with anastomosis; 11 of 12 patients are well after excision of the rectum with colostomy. 
Many of these latter patients were young and the operation was undertaken with extreme reluctance. Each patient was disabled by ano-rectal disease and the good results obtained have justified the procedure in every case. When proctocolectomy has been required, the results have usually been good and 21 of 28 patients are well.

After a resection for Crohn's disease of the colon, recurrence of the disease involving the remaining colon, the anus, or the skin around a colostomy or perineal wound cannot usually be distinguished from an exacerbation of pre-existing disease. One of the interesting results of the present survey is the apparently low incidence of recurrence in the ileum after colonic resection. To date, three ileal recurrences have been observed, one involving the ileostomy 13 years after proctocolectomy and two involving the ileum above an ileo-rectal anastomosis when the rectum was also diseased. The infrequency of ileal recurrence, with its sequelae of malabsorption and obstruction, has meant that nearly all the patients in this series have regained good health after treatment, in most cases by excision of the diseased bowel.

The results of this survey suggest that while medical treatment, particularly with corticosteroids, often leads to symptomatic improvement, it does not often result in permanent benefit. Diversion operations are rarely helpful as a treatment for colonic or anal disease. Where the disease is localized to part of the bowel, limited resection of the diseased area often leads to complete relief of symptoms, though recurrences occur and the length of follow-up is inadequate to assess this risk fully. When symptoms are severe and the disease involves most or all of the colon, and the rectum or anus, proctocolectomy appears the best treatment.

\section{SUMMARY}

The results of treatment have been reviewed in 96 patients with Crohn's disease of the large bowel. Medical treatment, including the use of corticosteroids, was often of symptomatic benefit but rarely led to permanent relief of symptoms. Eighty-four of the 96 patients have required surgical treatment. The results of diversion operations were unsatisfactory but limited resections for localized disease and total colectomy for diffuse disease have given good results. The incidence of recurrent disease in the ileum after excision of colonic Crohn's disease has been low.

We thank our colleagues at St. Mark's Hospital for permission to study patients under their care.

\section{REFERENCES}

Lockhart-Mummery, H. E., and Morson, B. C. (1960). Crohn's disease (regional enteritis) of the large intestine and its distinction from ulcerative colitis. Gut, 1, 87-105.

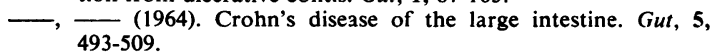

